A. Klimczuk, Work, Domestic Work, Emotional Labor, [in:] B. Turner, P. Kivisto, W. Outhwaite, C. Kyung-Sup, C. Epstein, J.M. Ryan (eds.), The Wiley-Blackwell Encyclopedia of Social Theory, WileyBlackwell, London 2017, pp. 1-4, http://dx.doi.org/10.1002/9781118430873.est0409.

\title{
Work, Domestic Work, Emotional Labor
}

\section{ANDRZEJ KLIMCZUK}

Warsaw School of Economics, Poland

The concept of work can be understood as a purposeful human activity, which is focused on the processing of natural goods, items, and/or information by using tools to meet the tangible and intangible needs. Work is the usage of instruments to support the existence of humankind and the social world.

From the perspectives of cultural anthropology, ethnology, and social constructionism activities known as work are determined by convictions in the individual social, cultural, and economic systems. Thus, things that in a given society may be regarded as work in another society can be considered, for example, as in the sphere of voluntary activity or free time. Work in any society is anchored in values that define its essence, meaning, and activities. In the history of mankind, "work" evolved from a wider sense (e.g., pillage, conquest, and war) to a narrow sense (e.g., hunting, gathering, fishing, farming, mining, industry, trade, services, research, coordination, planning). Performing the work is legitimized by the ideology of work, myths, and religious ideas about the meaning of work and cultural norms.

According to the structural-functional theory, work can be defined as activities such as voluntary service in the military, sports, prayer, and artistic work if they contribute to the functioning of the social system by sustaining human existence. In contemporary market systems, human labor is defined as the activity leading to a measurable benefit valued in the market as income. Connected to this are difficulties in estimating the benefits of volunteer work, social and political activities, and women's work in households.

Human work is also distinguished from animal work (Hodson and Sullivan 2012). Humankind, unlike other species, identifies a larger variety of ways of dealing with the environment. It is impossible to explain human work as an action based solely on instincts. Moreover, there is a diversity of activities undertaken by individuals in the labor process. Human work is characterized by intraspecific cooperation in the environmental impact and the diversity of forms of work organization. This also leads to intra- and intergroup power relations, conflicts related to the scarcity of natural resources, and the norms for the maintenance of social order.

Studies of the value systems show that work has a particular significance for people alongside the family, health, and religious denomination. The importance of work, however, 
A. Klimczuk, Work, Domestic Work, Emotional Labor, [in:] B. Turner, P. Kivisto, W. Outhwaite, C. Kyung-Sup, C. Epstein, J.M. Ryan (eds.), The Wiley-Blackwell Encyclopedia of Social Theory, WileyBlackwell, London 2017, pp. 1-4, http://dx.doi.org/10.1002/9781118430873.est0409.

also depends on factors such as country, occupational group, a branch of the economy, gender, age, education, and family situation. Long-term unemployment not only leads to loss of income and consumption but also to reduce social contacts, conflicts in the family, loss of respect, and deterioration of mental and physical health. The work is valued because of punitive, instrumental, or autotelic reasoning. The punitive reasoning considers the work as the imposed institution (by society, the state, the market, and the ruling class) under coercion (economic, ideological, legal, and normative). The person then treats a job as bad luck. Instrumental justification indicates the individual and social benefits of work. A person who works recognizes the work as the basis of existence. Autotelic justification assumes that work is an end in itself, the source of humanity, and personal growth. This dimension of the work is emphasized in the paradigms of human resources and human capital management developed from the end of the twentieth century.

Work is also described from the perspective of the types of work and activities. These descriptions include job analysis as an element of social stratification and colloquial perception of work in the professional categories and workplaces that have emerged along with the division of labor and the emergence of a market economy. These categories relate to, for example, physical work, domestic work, office work, service work, managerial work, agricultural work, and work associated with organized crime.

Moreover, the transformation of human labor includes changes in the technology of work that affects human activities and feelings associated with work (Boreham et al. 2008; Hodson and Sullivan 2012). A shift from the "work as part of being in the world" to "dematerialization of work" is observed. The first phase concerned hunter-gatherer communities where the work determined other activities according to a daily rhythm of hunger and satiation. This type of work did not force the accumulation of surpluses and did not create social divisions. The work was defined as a task, in communities settled around the sixth millennium BCE. There was a division between working and nonworking populations, broken down based on the place of birth and heredity, and justified by religious beliefs. Jobs then focused on food production and maintaining a territory. In the nineteenth century when industrialization and urbanization "work denaturalization" occurred. Employment began to be justified on economic grounds and specialization. Work activities were tied to industrial production and administrative work. Work ceased to be exclusively subordinated to nature and for the sustenance of human life. This stage is characterized by the phenomenon of Fordism, which refers to the organization of production on a massive scale using the production line. This organization of work leads to the routine and 
A. Klimczuk, Work, Domestic Work, Emotional Labor, [in:] B. Turner, P. Kivisto, W. Outhwaite, C. Kyung-Sup, C. Epstein, J.M. Ryan (eds.), The Wiley-Blackwell Encyclopedia of Social Theory, WileyBlackwell, London 2017, pp. 1-4, http://dx.doi.org/10.1002/9781118430873.est0409.

monotony of work, limiting a man to perform only several tasks, and degrading people to the role of controlled tools. At the end of the twentieth century and the start of the twenty-first century, Fordism as a production system moves from the countries of the Global North to the Global South. "Work dematerialization" has been in progress since the 1980s, along with globalization and the use of information and communications technologies (ICTs). Mass production is limited in the countries of the Global North; instead, there are more intellectual activities and human resource management of teams, which aims to generate projects of new items, services, and high technologies. Work begins to be an autotelic value, not an instrumental value. At the same time, the importance of technological unemployment is observed, which relates to the restructuring of industry and agriculture and reduction of the work demand (Rifkin 1995).

Another issue is the socialization to work through family, school, peer group, mass media, and making the work environment (Volti 2012). This process involves overcoming the contradictions between professional role and other roles (work-life balance), gaining space in the occupational structure, learning and assimilation of organizational culture (including different dimensions of national cultures such as organization's vision, values, norms, work ethic, symbols, language, beliefs, and habits), development of cooperation skills with the working group, and subordination to the orders of superiors. Gender differentiates socialization to work; for example, some societies exclude women from certain occupations and expect women to be housekeepers. Management of duties related to running a household may also be delegated to non-household members hired to perform them.

Domestic work refers to the work of domestic help, which are usually individuals who work and often live in the house of the employer. A domestic worker, however, is not a slave (the person who is the property of others) or serf (a free compulsory employee performing work as feudal rent to the landowner in the dimension determined unilaterally by him or by customary or legal rules). However, due to weak regulations in many countries, domestic workers such as women and migrant workers are subject to abuses such as slavery, illegal child labor, forced labor, trafficking, and informal employment.

Domestic workers receive remuneration for their work and service and may be dismissed at any time. Activities of work performed by domestic workers include household services such as providing care for children and elderly, cleaning and household maintenance, cooking, laundry, and shopping. The domestic work industry practices were harder before the industrial revolution. However, it still reinforces gender inequality by the domination of women's 
A. Klimczuk, Work, Domestic Work, Emotional Labor, [in:] B. Turner, P. Kivisto, W. Outhwaite, C. Kyung-Sup, C. Epstein, J.M. Ryan (eds.), The Wiley-Blackwell Encyclopedia of Social Theory, WileyBlackwell, London 2017, pp. 1-4, http://dx.doi.org/10.1002/9781118430873.est0409.

employment. Housekeeping and domestic work include jobs such as an au pair, babysitter, maid, butler, chauffeur, cleaner, cook, dog walker, footman, gardener, governess, hall boy, handyman, horse trainer, laundress, masseur or masseuse, nursemaid, personal shopper, personal trainer, pool person, security guard, shoe shiner, stable boy, and wet nurse.

Concepts of emotion work and emotional labor were introduced by the US sociologist Arlie Hochschild $(1979,1983)$ in her study of flight attendants and bill collectors. She argues that such jobs are characterized by emotional and service aspects and are done mainly by women. Other examples are waitresses, nurses, amusement park greeters, insurance agents, nail salon attendants, food handlers, and emergency operators. Emotion work includes the psychological processes necessary to regulate emotions that are desired in a private/personal arena. At the same time, emotional labor is called "selling feelings" as a commodity and paid employment that involves work performed by using feelings. Service economies include jobs characterized by emotional labor, such as airline flight attendant, waitress, and bartender.

According to Hochschild, emotion work is the effort involved in manipulating emotions in oneself and others and generating feelings that are appropriate for a situation. This is always the act of trying and may lead or not to successful outcomes. Emotion work includes both shaping and suppressing feelings in the private context of family and friends, whereas emotional labor takes place in the public sphere as a social and economic exchange sold for wages during interactions with customers or co-workers that demand displaying and expressing certain emotions according to organizational aims.

Two basic types of emotion work are evocation (focus on an initially absent desired feeling) and suppression (focus on an initially present undesired feeling). Basic techniques of emotion work are (1) a cognitive attempt to change images, thoughts aimed at changing associated feelings; (2) bodily attempt to change physical symptoms of emotions (for example, slow breathing); and (3) expressive attempts to change gestures (for example, trying to smile).

Emotional labor is characterized by face-to-face or voice-to-voice interactions with clients (for example, patients, children, customers, passengers, or guests); inclusion of the behavioral expressions that aim to change others' emotions, attitudes, and behavior; and displaying of emotions related to social expectations. Emotional labor may be described by the episodes (for example, dealing with an angry customer before or after dealing with an angry co-worker), by the job (different professions; possibilities of controlling other employees), and by the person (different individual characteristics) (Ashkanasy and Cooper 2008).

Contemporary companies attempt to support emotional labor as it may influence client and 
A. Klimczuk, Work, Domestic Work, Emotional Labor, [in:] B. Turner, P. Kivisto, W. Outhwaite, C. Kyung-Sup, C. Epstein, J.M. Ryan (eds.), The Wiley-Blackwell Encyclopedia of Social Theory, WileyBlackwell, London 2017, pp. 1-4, http://dx.doi.org/10.1002/9781118430873.est0409.

service-user satisfaction. It may create more predictable social interactions and help to avoid embarrassing situations. Emotional labor also builds trust in the organization; improves customer loyalty; provides a higher assessment of the service quality; displays positive emotions, cognition, and behavior of clients; and makes for the easier performance of tasks (for example, dentist cheering a child up to carry out the treatment). Emotional labor may be the goal itself in the entertainment business and the helping professions (for example, psychotherapist, hostess).

At the beginning of the twenty-first century, emotion work and emotional labor were also further described as the "intimate labor" (Parreńas and Boris 2010). Intimate labor includes occupations related to care, domestic, and sex work that involves bodily and psychic intimacy (for example, manipulating genitalia, wiping noses, lifting torsos, feeding, listening, talking, and holding). These labors are stigmatized by their relation to dirt, bodies, and intimacy. Another variant is "embodied labor," which may be described by, for example, a commercial surrogacy, which includes a rental of one's body by somebody else, the use of the body of the worker as a site, resource, requirement, and product. It also refers to fields of resistance and negotiations between the surrogate, the family, the clinic, and the state (Pande 2014).

SEE ALSO: Caring; Division of Labor; Domestic Sphere; Gender Segregation in Work; Household Production; Manual and Mental Labor; Sociology of Work

\section{REFERENCES}

Ashkanasy, Neal M. and Cooper, Cary L., eds. 2008. Research Companion to Emotion in Organizations. Cheltenham, UK: Edward Elgar.

Boreham, Paul, Parker, Rachel, Thompson, Paul, and Hall, Richard. 2008. New Technology

@ Work. London: Routledge.

Hochschild, Arlie R. 1979. Emotion Work, Feeling Rules, and Social Structure. American Journal of Sociology, 85(3): 551-575.

Hochschild, Arlie R. 1983. The Managed Heart: Commercialization of Human Feeling. Berkeley: University of California Press.

Hodson, Randy and Sullivan, Teresa A. 2012. The Social Organization of Work, 5th edn. Belmont, CA: Cengage Learning.

Pande, Amrita. 2014. Wombs in Labor: Transnational Commercial Surrogacy in India. New York: Columbia University Press. 
A. Klimczuk, Work, Domestic Work, Emotional Labor, [in:] B. Turner, P. Kivisto, W. Outhwaite, C. Kyung-Sup, C. Epstein, J.M. Ryan (eds.), The Wiley-Blackwell Encyclopedia of Social Theory, WileyBlackwell, London 2017, pp. 1-4, http://dx.doi.org/10.1002/9781118430873.est0409.

Parrenas, Rhacel S. and Boris, Eileen, eds. 2010.

Intimate Labors: Cultures, Technologies, and the Politics of Care. Stanford, CA: Stanford Social Sciences.

Rifkin, Jeremy. 1995. The End of Work: The Decline of the Global Labor Force and the Dawn of the Post-market Era. New York: Putnam.

Volti, Rudi. 2012. An Introduction to the Sociology of Work and Occupations, 2nd edn. Thousand Oaks, CA: SAGE.

\section{FURTHER READING}

Donkin, Richard. 2010. The Future of Work. Basingstoke, UK: Palgrave Macmillan.

Gutierrez Rodnguez, Encarnación. 2010. Migration, Domestic Work and Affect: A Decolonial Approach on Value and the Feminization of Labor. New York: Routledge.

Guy, Mary E., Newman, Meredith A., and Mastracci, Sharon H. 2008. Emotional Labor:

Putting the Service in Public Service. Armonk, NY: M.E. Sharpe.

Sieben, Barbara and Wettergren, Asa, eds. 2010. Emotionalizing Organizations and

Organizing Emotions. New York: Palgrave Macmillan.

Treas, Judith and Drobnic, Sonja, eds. 2010. Dividing the Domestic: Men, Women, and Household Work in Cross-National Perspective. Stanford, CA: Stanford University Press. 